\title{
Self-Enhancement and Social Responsibility: On Caring More, but Doing Less, Than Others
}

\author{
Jonathan A. White and S. Plous
}

Wesleyan University

Self-enhancement biases have been found in a variety of self-rated skills, traits, and abilities, yet past research has not examined whether people show such biases in ratings of their social concem and activism. In the present paper, we report the results of two surveys on this question. In the first survey, 549 adults rated their level of concern and activism on one of six different issues (e.g., homelessness). The results showed a general pattern of self-enhancement in professed concern but self-deprecation in activism. In the second survey, a random-digit dialing method was used to contact a representative sample of the general public. A total of 817 respondents rated their level of concern and activism on the issues of environmental protection, animal welfare, and world hunger. The second survey also explored two techniques for debiasing self-enhancement in concern: one based on a cognitive consistency model, and one based on the salience of others' actions. Findings from the second survey replicated those of the first, and both debiasing techniques failed to reduce self-ratings of concern. Moreover, a sizable number of respondents said that they would do more if others showed more concern. These results are consistent with a social dilemma in which citizens feel a personal sense of concern, but are reluctant to act until others show greater concern.

Most of us have it: the tendency to see ourselves as better than we really are. Self-enhancement biases have been found in such diverse domains as self-rated intelligence (Brim, Neulinger, \& Glass, 1965), driving skill (Robertson, 1977; Svenson, 1981), job performance (Blackburn, Pellino, Boberg, \& O'Connell, 1980), and athletic ability (Felson, 1981; VanYperen 1992). Self-enhancement has also been found in nonability domains, such as personality characteristics (Wylie, 1979), susceptibility to health risks (Weinstein, 1982, 1987), and the likelihood of behaving morally (Allison, Messick, \& Goethals, 1989).

The consequences of self-enhancement are both positive and negative. Taylor and Brown (1988) have stressed that "positive illusions" often allow people to remain healthy and happy in a sometimes-cruel world. Clearly, self-enhancing comparisons can reduce anxiety and bolster self-confidence

'Correspondence concerning this article should be addressed to S. Plous, Department of Psychology, Wesleyan University, Middletown, CT 06459-0408. 
(Perloff, 1983; VanYperen, 1992). Yet, self-enhancement biases have a down side, too. In some cases, they lead to a complacency in which people ignore legitimate risks (Lehman \& Taylor, 1988; Weinstein, 1982) and fail to take necessary actions or precautions (Perloff, 1983). For example, college women who harbor illusions of "unique invulnerability" about becoming pregnant are less likely than others to use effective contraception (Burger \& Burns, 1988). Similarly, people who believe they will not become sick are less likely than others to immunize themselves against the flu (Larwood, 1978).

One important, yet unexplored, area in which self-enhancement biases may lead to complacency is the domain of social concern and activism. If, for example, individuals believe that they are more concerned than others about the environment, or if they believe that they already do more than other people do, they may decide not to take further actions to protect the environment. This possibility is particularly likely given the fact that environmentalism and other forms of activism are positively associated with a personal sense of responsibility (Hines, Hungerford, \& Tomera, 1986; Tyler \& McGraw, 1983). To date, however, no researchers have suggested that self-enhancement biases in social concern may serve to impede activism.

\section{Methodological Considerations}

In order to document the presence of self-enhancement biases, certain methodological requirements must be met. Perhaps the most basic of these requirements is that comparisons be made against an appropriate reference group. When this condition is not fulfilled, it becomes difficult, if not impossible, to ascertain whether self-enhancement biases are present. For example, consider a College Entrance Examination Board (1977) report that is often cited as evidence of self-enhancement. In this study, over 800,000 SAT-takers nationwide completed a questionnaire in which they compared themselves with their classmates in several skills and abilities. The results seemed to suggest a number of self-enhancement biases: for instance, $57 \%$ of students rated themselves above average in mathematics, and $64 \%$ rated themselves above average in written expression. Yet the students who answered these questions represented less than one third of all high-school graduates-those who were taking the SAT and intended to go to college. Because these students may, in fact, have differed from others in math and writing, a more appropriate comparison group would have been other students taking the SAT.

Similar problems are evident in a well-known study by Larwood (1978), in which subjects rated themselves as healthier than "the average person." A portion of the respondents in this study were volunteers attending a college health fair; hence, it is reasonable to assume that these people were more health-conscious (and, quite possibly, healthier) than the average person. Inappropriate comparison groups are particularly problematic in studies that ask students to compare themselves with the average person rather than with other students (e.g., Furnham \& Dowsett, 1993). Indeed, even when student subjects are asked to compare themselves with other students, they are often drawn from a single class (e.g., introductory psychology) and are far from representative of the comparison group in general (e.g., all college students).

One means of avoiding interpretive problems is to randomly select subjects from the group that is used for comparison. Random sampling reduces the likelihood that respondents will differ from the comparison group on the dimensions being explored. 2 Unfortunately, only a handful of published studies have used random samples of the general public (Brim et al., 1965; Heiss \& Owens, 1972; Kirscht, Haefner, Kegeles, \& Rosenstock, 1966; Robertson, 1977; Weinstein, 1987). Traditionally, the most popular respondent in self-enhancement research has been the college student, and more often than not, samples have been based strictly on convenience.

In the present research, we used random sampling to investigate self-enhancement biases in social concern and activism. A preliminary survey was conducted by student interviewers to see whether self-enhancement biases exist on these dimensions. Self-enhancement was assessed in a number of ways (e.g., mean ratings and frequency distributions), allowing for a direct comparison of various methods that have been used in the past. Then, in the main study, a random-digit-dialing telephone survey was conducted to see whether these biases exist among a random sample of the general public. Because selfenhancement biases in social concern and action are potentially maladaptive, the main study also explored various debiasing techniques.

\section{Pilot Study}

In order to determine whether the general public exhibits self-enhancement biases in social concern and activism, a pilot survey was administered to passersby in several street-corner locations. Six different surveys were administered, covering the following issues: the environment, AIDS, animal protection, drug abuse, world hunger, and homelessness. These six issues were

${ }^{2}$ Even random sampling may not prevent interpretive problems, however, if data are missing from a substantial number of subjects. For instance, a study reported by Baumhart (1968) is widely cited as evidence that business executives see themselves as more ethical than others, yet the results are based on responses from only 1,531 executives out of an original sample of 5,000 (leaving open the possibility that the executives who answered the survey were, in fact, more concerned with ethics than were other executives) 
selected to represent a wide range of pressing societal problems. Self-enhancement was measured both through comparative ratings on single scales and through indirect comparisons of self-ratings and other-ratings. Finally, the inclusion of certain items adapted from previous national surveys permitted an assessment of the representativeness of the sample.

\section{Method}

Participants. Respondents were 549 adults who agreed to fill out a short survey that was part of a student project being conducted at Wesleyan University. All respondents were between the ages of 18 and $78(M=35.0)$; roughly $60 \%$ of respondents reported an educational level beyond high school; the median family income was "between $\$ 30,000$ and $\$ 40,000$ " per year; and the gender ratio was 1:1 (with 273 women, 274 men, and 2 respondents whose sex was not recorded). ${ }^{3}$ Ninety-one respondents completed a survey concerning the environment, 89 completed a survey concerning AIDS, 93 completed a survey concerning animal protection, 96 completed a survey concerning drug abuse, 96 completed a survey concerning world hunger, and 84 completed a survey concerning homelessness.

Procedure. Fifty-nine student interviewers administered one of the six surveys described below. Respondents were approached in public locations throughout Connecticut during the first 3 weeks of October 1992, based on an approach rule in which the first unaccompanied adult walking within $15 \mathrm{ft}$ of an interviewer was selected for inclusion. Each survey took approximately 5-10 min to complete. Survey interviewers were encouraged to choose diverse locations for administering the survey, and they were directed to conduct all surveys off-campus (to minimize the selection of university students and faculty as respondents).

Survey instrument. Each survey began with a question adapted from a Gallup Poll (1991) asking respondents to indicate whether they believed that the American public was "too worried," "not worried enough," or expresses the "right amount of concern" about the issue in question. ${ }^{4} \mathrm{~A}$ similarly worded item asked respondents to make the same judgment about their own level of

${ }^{3}$ In both the pilot study and the main study, no systematic gender or age differences were found on any of the dependent measures. Consequently, these factors are not discussed further.

${ }^{4}$ Surveys concerning the environment and animal protection differed from the others in that they initially asked respondents whether they considered themselves to be environmentalists (or animal rights supporters, depending on the survey). Nationwide surveys have found that $78 \%$ of respondents describe themselves as environmentalists, and $75-80 \%$ support animal rights (Gallup Poll, 1991; Plous, 1993). In the present study, 70\% of respondents described themselves as environmentalists, and $80 \%$ identified themselves as animal rights supporters. concern (e.g., "Do you feel that you are too worried, not worried enough, or express about the right amount of concern about the environment?"). Respondents were then asked to numerically rate their level of concern, compared with other people of their age and gender (on a 9-point rating scale with endpoints labeled less than most and more than most).

The next section of the survey presented respondents with a list of five to eight actions that were described as defining activism for that issue. ${ }^{5}$ The activities that were listed for all six issues included contributing money and volunteering time, talking to others about the issue, and reading about it. The remaining activities were specific to each particular issue. For example, the list of actions that defined "environmentalism" also included items on recycling, picking up litter, conserving energy, and so on. Respondents were asked to read the activity list and rate both their overall level of activism (e.g., "Using this definition of activism and comparing yourself with other people of your age and sex, how active have you been in working to protect the environment?") and the relative frequency that they engaged in each of the activities (e.g., "Compared with other people of your age and sex, how frequently do you contribute time or money to an environmental group?"). In both cases, ratings were made on 9-point scales. After these items, respondents were asked a series of standard demographic questions.

\section{Results}

As shown in Figure 1, the pattern of responses was similar for all issues except environmentalism. Respondents tended to display self-enhancement in ratings of their concern, but self-deprecation in ratings of their activism. Results are described below, first for ratings of concern and then for ratings of activism.

Concern ratings. Self-enhancement was found in social concern across all six issues. As seen in the second column of Table 1, the mean self-rating of concern was greater than the midpoint of the scale for each of the six issues examined. Scores ranged from 5.62 (hunger) to 6.55 (AIDS), with an overall mean of 6.09 . Two-tailed $t$ tests using a midpoint of 5.00 as the expected value under the null hypothesis revealed that these differences were highly significant for each issue (all $p \mathrm{~s}<.005$ ).

To analyze the frequency distribution of scores, ratings on the 9-point concern scale were trichotomized into groups ranging from less than others (1-4), same as others (5), and more than others (6-9). Columns 4-6 of Table 1

${ }^{5}$ These lists of actions were developed through earlier pretests on 153 college students and were intended to represent a fairly exhaustive list of common actions taken for each issue. 


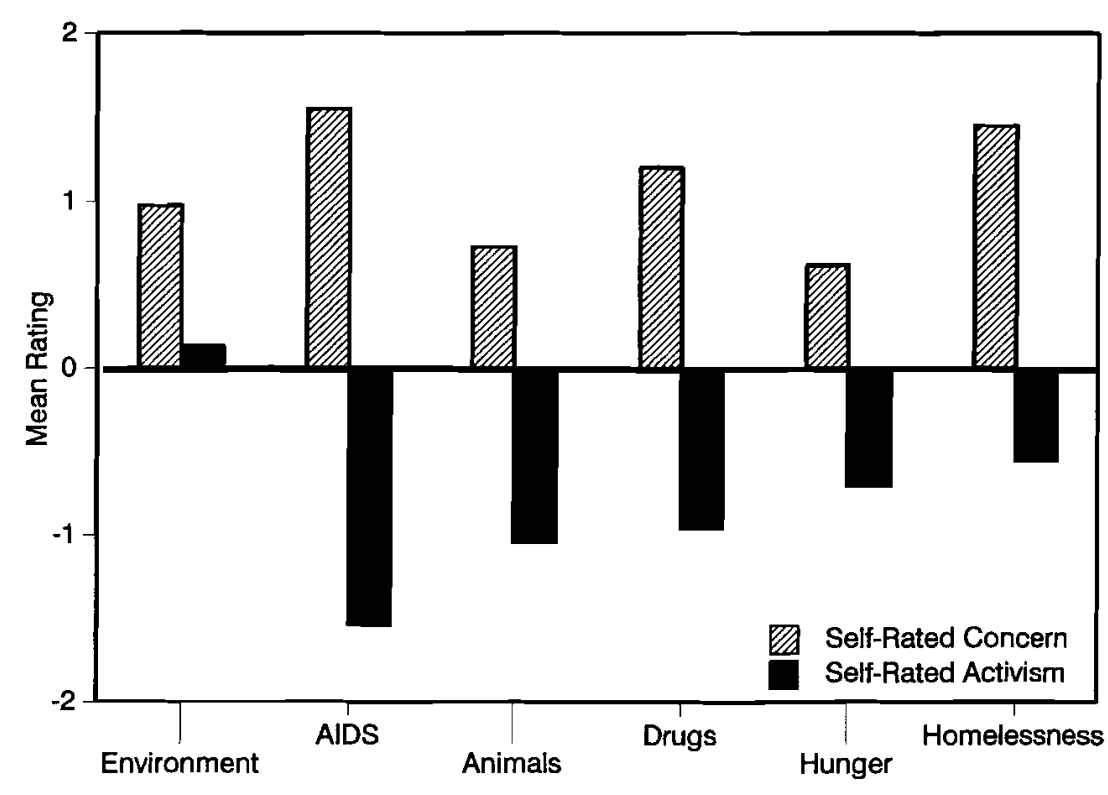

Figure 1. Mean self-ratings for concern and activism in the pilot study. (Numbers along the y-axis represent deviations from the midpoint of 5.00 on a 9-point scale; see text for explanation of dependent measures.)

show that for all six issues, a plurality of respondents fell into the more than others category. Following Segerstrom, McCarthy, Caskey, Gross, and Jarvik (1993), the frequency distribution that would be expected by chance was derived by evenly dividing the number of respondents who did not fall into the same as others category, and assigning these frequencies to the other two categories (e.g., expected frequencies concerning the environment were based on the proportions $.407, .187$, and .407 , since $18.7 \%$ of respondents reported their environmental concern as same as others). Chi-square goodness-of-fit tests led to a rejection of the null hypothesis for all six issues: $9.62<\chi^{2}$ s $<$ 38.48 , all $p$ s $<.009$.

Self-enhancement in concern was also apparent from answers to the questions adapted from the Gallup Poll. In a national survey of American adults, the Gallup Poll (1991) found that 70\% of respondents thought the American public was not worried enough about the environment, $22 \%$ thought the public showed the right amount of concern, and $6 \%$ believed the public was too worried ( $2 \%$ had no opinion). Data from the present study were comparable to those found by Gallup: $67.0 \%$ of respondents reported that the public is not
Table 1

Mean Scores and Frequency Distributions for Self-Ratings of Social Concern: Pilot Study

\begin{tabular}{|c|c|c|c|c|c|c|}
\hline \multirow[b]{2}{*}{ Issue } & \multicolumn{2}{|c|}{ Mean ratings } & \multicolumn{4}{|c|}{ Distribution of scores } \\
\hline & $M$ & $p^{\mathrm{a}}$ & $\begin{array}{l}\text { Less than } \\
\text { others (\%) }\end{array}$ & $\begin{array}{c}\text { Same as } \\
\text { others (\%) }\end{array}$ & $\begin{array}{l}\text { More than } \\
\text { others (\%) }\end{array}$ & $p^{\mathrm{b}}$ \\
\hline Environment & 5.98 & .001 & 23.1 & 18.7 & 58.3 & .001 \\
\hline AIDS & 6.55 & .001 & 11.2 & 18.0 & 70.8 & .001 \\
\hline Animal protection & 5.73 & .001 & 21.5 & 22.6 & 55.9 & .001 \\
\hline Drug abuse & 6.20 & .001 & 15.6 & 19.8 & 64.6 & .001 \\
\hline World hunger & 5.62 & .004 & 21.1 & 31.6 & 47.3 & .008 \\
\hline Homelessness & 6.45 & .001 & 8.3 & 28.6 & 63.1 & .001 \\
\hline
\end{tabular}

aSignificance levels refer to two-tailed $t$ tests of the null hypothesis that the mean rating is equal to 5.00 (the midpoint of the rating scale). bSignificance levels refer to goodness-of-fit tests of the null hypothesis that frequencies in the more than others and less than others categories are equal.

worried enough about the environment, $24.2 \%$ reported that the public shows the right amount of concern, and $8.8 \%$ reported that the public is too worried (with similar results on the other five issues). When asked about their own level of concern, however, respondents typically reported having the "right amount of concern" (Table 2). After collapsing "too worried" and "not worried enough" into one category (to avoid low expected frequencies), McNemar tests of symmetry were performed to determine whether the paired distributions in Table 2 were independent. These tests showed that respondents ascribed the "right amount of concern" to themselves more often than to the public on all six issues (all $p \mathrm{~s}<.001$ ).

Activism ratings. A very different picture emerged with respect to activism. As seen in Table 3, averaged self-ratings of activism fell below the midpoint of the scale for five out of six issues. Mean activism ratings for these five issues ranged from 3.46 (AIDS) to 4.44 (homelessness), and two-tailed $t$ tests revealed that all of these means were significantly lower than the expected mean of 5.00, all $p s<.007$. The one exception to this trend was self-rated environmental activism, which did not differ significantly from the midpoint of the scale $(M=5.14), t(89)=0.70, n s$. Table 3 also shows that on all issues except 
Table 2

Response Frequencies for Questions on Public Concern and Self-Rated Concern

\begin{tabular}{llrr}
\hline \multicolumn{1}{c}{ Issue } & \multicolumn{1}{c}{ Response } & Public (\%) & Self (\%) \\
\hline Environment & Not worried enough & 67.0 & 42.9 \\
& Right amount of concern & 24.2 & 51.6 \\
& Too worried & 8.8 & 5.5 \\
AIDS & Not worried enough & 71.9 & 21.3 \\
& Right amount of concern & 21.3 & 70.8 \\
& Too worried & 6.7 & 7.9 \\
Animal protection & Not worried enough & 59.8 & 30.1 \\
& Right amount of concern & 29.3 & 68.8 \\
& Too worried & 10.9 & 1.1 \\
Drug abuse & Not worried enough & 66.7 & 25.3 \\
& Right amount of concern & 26.0 & 69.5 \\
& Too worried & 7.3 & 5.3 \\
World hunger & Not worried enough & 70.8 & 47.9 \\
& Right amount of concern & 21.9 & 49.0 \\
& Too worried & 7.3 & 3.1 \\
& Not worried enough & 75.0 & 39.3 \\
Homelessness & Right amount of concern & 23.8 & 56.0 \\
& Too worried & 1.2 & 4.8 \\
\hline
\end{tabular}

the environment, the majority of activism self-ratings fell below the midpoint (with four of these issues-AIDS, animal protection, drug abuse, and hunger-reaching statistical significance).

\section{Discussion}

Based on these results, it seems that people tend to show self-enhancement when it comes to concern and self-deprecation when it comes to activism. On all six issues examined, respondents stated that they were more concerned
Table 3

Mean Scores and Frequency Distributions for Self-Ratings of Activism: Pilot Study

\begin{tabular}{|c|c|c|c|c|c|c|}
\hline \multirow[b]{2}{*}{ Issue } & \multicolumn{2}{|c|}{ Mean ratings } & \multicolumn{4}{|c|}{ Distribution of scores } \\
\hline & $M$ & $p^{\mathrm{a}}$ & $\begin{array}{l}\text { Less than } \\
\text { others (\%) }\end{array}$ & $\begin{array}{c}\text { Same as } \\
\text { others (\%) }\end{array}$ & $\begin{array}{l}\text { More than } \\
\text { others (\%) }\end{array}$ & $p^{\mathrm{b}}$ \\
\hline Environment & 5.14 & .486 & 41.1 & 2.2 & 56.7 & .328 \\
\hline AIDS & 3.46 & .001 & 82.0 & 2.2 & 15.7 & .001 \\
\hline Animal protection & 3.95 & .001 & 73.6 & 3.3 & 23.1 & .001 \\
\hline Drug abuse & 4.04 & .001 & 67.4 & 5.3 & 27.4 & .001 \\
\hline World hunger & 4.28 & .001 & 61.7 & 5.3 & 33.0 & .017 \\
\hline Homelessness & 4.44 & .007 & 58.0 & 6.2 & 35.8 & .119 \\
\hline
\end{tabular}

asignificance levels refer to two-tailed $t$ tests of the null hypothesis that the mean rating is equal to 5.00 (the midpoint of the rating scale). bSignificance levels refer to goodness-of-fit tests of the null hypothesis that frequencies in the "more than others" and "less than others" categories are equal.

than other people of their age and gender, yet on five of the issues, they reported doing less than others. These findings are consistent with past research showing that self-enhancement is most likely when the evaluative dimensions are ambiguous (Felson, 1981; VanYperen, 1992). Because "concern" was not explicitly defined in the survey, respondents had a great deal of latitude in rating themselves on this dimension. In contrast, activism was broken down into a set of concrete, observable actions which did not allow the same kind of flexibility.

Indeed, not only was there a lack of self-enhancement for activism, but respondents actually tended to rate themselves as less active than others. This trend toward self-deprecation was strongest for the issues of AIDS, animal protection, and drug abuse; it was evident but somewhat weaker for the issues of world hunger and homelessness; and it was not observed for environmental activism. These differences are probably a function of differing base rates of participation and differing levels of activist media exposure across the six issues. For example, the low activism self-ratings for AIDS, animal protection, and drug abuse were probably due to respondents comparing themselves with rare but highly visible activists who are involved in these issues. In contrast, 
activists working to end hunger and homelessness are far less visible, and public participation in these issues is somewhat more common (if only in the form of giving spare change to homeless people or contributing items to a food drive). Environmental activism is still more common (Gallup Poll, 1991), with some activities having very high rates of participation or even being mandated by law (e.g., recycling, conserving resources)

Of course, one explanation for above-average ratings in social concern is that respondents actually were more concerned than were others of their age and gender. Yet there are a number of reasons to doubt this explanation. First, the proportion of respondents who identified themselves as environmentalists or animal rights supporters corresponded closely to the proportion found in national samples. Responses to the question on public concern about the environment were also very similar to those obtained in a national survey (Gallup Poll, 1991). Because respondents did not differ from the general public on these questions, it is unlikely that they harbored an unusually high degree of social concern (at least with respect to animals and the environment) Moreover, according to the respondents themselves, they were not more actively involved than were others of their age and gender.

In general, then, it appears that: (a) people display self-enhancement in ratings of their concern; (b) people frequently, though not always, display self-deprecation in ratings of their activism; and (c) the self-enhancement people display in social concern does not rest on a belief that they are more active than others. There are, however, certain weaknesses of the pilot study that limit the strength of these findings. First, the survey was conducted by a arge number of student interviewers, many of whom had little prior experience in administering surveys. Second, the sample was not drawn randomly, and may have been subject to undetected selection biases. Third, the pilot study relied on face-to-face interviews, which may have increased socia desirability pressures and thereby encouraged self-enhancement. To remedy these limitations, a second survey was conducted using a random-digit-dialing approach and a small staff of trained telephone interviewers. In addition, this survey further examined the discrepancy between self-rated concern and selfrated activism, and it explored methods of debiasing self-enhancement in concern.

\section{Main Study}

The purpose of this study was to replicate and extend findings from the pilot study by surveying a random sample of the general public. Of the six issues that were used in the pilot study, three were retained for inclusion in this survey: the environment, animal protection, and world hunger. These issues represented diverse social problems with widely differing degrees of public involvement.

As mentioned earlier, one potentially negative consequence of selfenhancement in social concern is that it can foster inaction. For example, if people feel that they are more concerned than others are about the environment, they may be reluctant to act until others show greater concern. In light of this possibility, a secondary purpose of the present study was to examine two different techniques for reducing self-enhancement biases in concern. For ease of reference, these techniques will be referred to as the consistency debiasing technique and the salience debiasing technique. The consistency technique was based on a cognitive consistency model that assumed respondents would attempt to minimize discrepancies between self-ratings of concern and selfreports of behavior (cf. Chaiken \& Baldwin, 1981). Because respondents in the pilot study reported relatively low levels of activism, it was predicted that self-enhancement biases in concern would be reduced by asking respondents to first consider their degree of activism on an issue. Two variations of the consistency technique were tested: consistency/public and consistency/private. In the public variation, respondents answered the questions on activism in the normal fashion (i.e., out loud). In the private variation, they were instructed to answer each question on activism silently, without sharing their answers with the interviewer (after which they publicly rated their level of concern). The latter condition was included in order to separate the effects of cognitive consistency from demand characteristics to appear outwardly consistent.

The salience technique was adapted from Weinstein and Lachendro (1982), who found that unrealistic optimism concerning various risks was reduced when students first considered the risk status of a "typical student." In the present study, self-ratings of concern were preceded by a request for respondents to think of activities that other people undertake for the issue in question. It was predicted that self-enhancement biases in concern would be reduced when the extent of other people's involvement in an issue was made more salient.

Finally, because self-ratings of concern and activism were so disparate in the pilot study, the main study included several questions exploring the relationship between these two dimensions. Specifically, respondents were asked: (a) whether their actions showed their level of concern about an issue, or whether they felt more concern than their actions showed; (b) whether they felt they would be more active if others showed greater concern about the issue in question; (c) which they thought was a better measure of their concern about an issue - how they felt about the issue, or what they did about it; and (d) which they thought was a better measure of citizen concern-how people felt about the issue, or what people did about it. 


\section{Method}

Participants. A random-digit dialing approach with three callbacks was used to contact 1366 households in central Connecticut. Of those who were called, $833(61.0 \%)$ completed the survey, $510(37.3 \%)$ refused, and $23(1.7 \%)$ terminated the survey prior to completion. Sixteen surveys were later discarded due to omitted or unusable responses, leaving a total of 817 respondents. A within-household quota system was used to ensure that the gender ratio of the sample was nearly 1:1 (413 females and 404 males). The median age of respondents fell in the category of 35-44 years old, which matched the regional median age of the adult population reported by the Census Bureau. Respondents' median education level was an associate degree, which was somewhat higher than the median education level for the area (high-school graduate).

Procedure. Respondents were contacted via telephone by one of four trained interviewers who presented the study as "a survey of Connecticut residents on their opinions concerning various social issues." Only individuals who were 18 years of age or older were asked to participate. Before beginning the survey, respondents were told that their name and address were unknown to the interviewer, and they were assured that their responses would remain confidential. Interviews typically took 5-10 min to complete.

Three social issues were examined: the environment, animal protection, and world hunger. Respondents were randomly assigned to answer questions about two of these three social issues, and the order of issue pairings was counterbalanced, thereby creating six permutations (environment-animal protection, animal protection-environment, environment-hunger, hungerenvironment, animal protection-hunger, hunger-animal protection). In addition, the first social issue in each survey was presented in one of three different formats: replication, consistency/public, or consistency/private (see Debiasing conditions). In all, then, there were 18 different survey variations (6 issue permutations $\times 3$ formats).

Survey instrument. The survey was similar in wording and content to the pilot survey, and the actions listed for each issue were identical to those used earlier. For ease of administration via the telephone, self-ratings of social concern were made on a scale ranging from -10 to +10 , with 0 indicating a level of concern equal to others, and self-ratings of activism were reduced to simple trichotomies (e.g., "Compared with other people of your age and sex, how frequently do you contribute time or money to an environmental group-more than average, less than average, or about average?"). After these questions, interviewers asked two questions intended to explore the relationship between concern and action. First, respondents were asked whether the actions they took showed their degree of concern about the issue, or whether they felt more concern than their actions showed. Second, respondents were asked whether they would do more about the issue if other people showed more concern about it (e.g., "Do you feel you would do more to protect the environment if other people showed more concern about protecting it?").

The interviewers then informed respondents that the next several questions would refer to a different issue than the one previously discussed. The first of these items was an open-ended question asking respondents to list at least three activities that other people did with respect to the issue. For example, for the issue of animal protection, the question was worded as follows: "First, I'd like you to take a moment to think about the things that other people do to protect animals. Take your time thinking about it, and tell me what activities come to mind." This question constituted the salience debiasing manipulation.

Respondents were next asked about public concern over the issue (with the item adapted from the Gallup Poll, 1991), and they were asked to rate their own level of concern from -10 to +10 , as they had for the first issue. This rating was followed by questions on: (a) whether respondents believed that their actions showed their level of concern about the issue, and (b) whether respondents felt that they would be more active if other people showed more concern. Finally, respondents were asked whether their feelings or their actions were a better reflection of the concern they felt (e.g., "When you think about your own level of concern about an issue, which is a better measure-how you feel about the issue, or what you do about it?"), and whether the same held true in judging other people (e.g., "Which do you believe is a better measure of citizen concern about an issue-how people feel about it, or what people do about it?"). ${ }^{6}$ The interview concluded with a series of standard demographic questions.

Debiasing conditions. As mentioned above, respondents were randomly assigned to either a replication condition or one of two consistency debiasing conditions. The replication condition followed the general format of the pilot study, in which respondents rated their level of concern about an issue before rating their level of activism. In the consistency/public condition, the order of questions was changed so that the questions on activism preceded the selfrating of concern. In the consistency/private condition, questions were asked in the same order as the consistency/public condition (i.e., activism preceding concern), but the interviewers instructed respondents to answer the activism questions silently:

${ }^{6}$ The latter two questions, asking respondents first about themselves and then about others, were added late in the data collection phase. Therefore, the analysis of these data is based on answers from only 96 respondents. 
I'm going to do something that isn't often done in telephone surveys. I'm going to read you a series of eight [five] questions but I don't want you to tell me your answers to them. Just think about each question and come up with an answer in your mind, but don't say it out loud. When you have your answer, just say "Okay," and I'll go on to the next question. Then, after these eight [five] questions, I'll ask you to answer some other questions out loud. Are these instructions clear?

After respondents in the consistency/private condition had silently formed answers to the questions on activism, they then rated their level of concern out loud, as in the other conditions.

In all, 268 respondents were assigned to the replication condition, 277 to the consistency/public condition, and 272 to the consistency/private condition. Because the format for the salience debiasing technique was the same in all surveys, all respondents were exposed to the salience manipulation.

Results

Concern ratings. As shown in Table 4, self-enhancement was found in ratings of concern for all three issues. Two-tailed $t$ tests using zero as the expected value under the null hypothesis revealed significant differences on al three issues: for the environment $(M=3.61), t(541)=21.40, p<.001$; for animal protection $(M=2.25), t(550)=11.69, p<.001$; and for world hunger $(M=2.49), t(541)=14.13, p<.001$. Self-enhancement was also found in the frequency distribution of scores. Using the same method of analysis as in the pilot study, ratings were trichotomized into groups corresponding to less than others (below zero), same as others (zero), and more than others (above zero) Chi-square goodness-of-fit tests led to a rejection of the null hypothesis for all three issues: for the environment, $\chi^{2}(2, N=542)=285.09, p<.001$; for animal protection, $\chi^{2}(2, N=551)=117.25, p<.001$; and for world hunger, $\chi^{2}(2$, $N=542)=163.10, p<.001$. These findings strongly replicate the pilot study.

Activism ratings. Scores for activism were calculated by averaging responses to each of the questions on specific actions (coding more than average as 1 , about average as 0 , and less than average as -1). Because an ANOVA crossing order of presentation (activism questions first vs. concern question first) yielded no significant differences due to order, activism scores were combined across the replication and consistency/public conditions. ${ }^{7}$

${ }^{7}$ Activism ratings from respondents in the consistency/private condition were never shared with the interviewer, and did not enter into this set of analyses.
Table 4

Mean Scores and Frequency Distributions for Self-Ratings of Social Concern: Main Study

\begin{tabular}{|c|c|c|c|c|c|c|}
\hline \multirow[b]{2}{*}{ Issue } & \multicolumn{2}{|c|}{ Mean ratings } & \multicolumn{4}{|c|}{ Distribution of scores } \\
\hline & $M$ & $p^{\mathrm{a}}$ & $\begin{array}{l}\text { Less than } \\
\text { others }(\%)\end{array}$ & $\begin{array}{c}\text { Same as } \\
\text { others }(\%)\end{array}$ & $\begin{array}{l}\text { More than } \\
\text { others (\%) }\end{array}$ & $p^{\mathrm{b}}$ \\
\hline Environment & 3.61 & .001 & 5.5 & 26.9 & 67.5 & .001 \\
\hline Animal protection & 2.25 & .001 & 13.2 & 36.8 & 49.9 & .001 \\
\hline World hunger & 2.49 & .001 & 9.0 & 39.1 & 51.8 & .001 \\
\hline
\end{tabular}

asignificance levels refer to two-tailed $t$ tests of the null hypothesis that the mean rating is equal to zero ("exactly average"). bSignificance levels refer to goodness-of-fit tests of the null hypothesis that frequencies in the more than others and less than others categories are equal.

Table 5

Mean Scores and Frequency Distributions for Self-Ratings of Activism: Main Study

\begin{tabular}{|c|c|c|c|c|c|c|}
\hline \multirow[b]{2}{*}{ Issue } & \multicolumn{2}{|c|}{ Mean ratings } & \multicolumn{4}{|c|}{ Distribution of scores } \\
\hline & $M$ & $p^{\mathbf{a}}$ & $\begin{array}{l}\text { Less than } \\
\text { others }(\%)\end{array}$ & $\begin{array}{c}\text { Same as } \\
\text { others (\%) }\end{array}$ & $\begin{array}{l}\text { More than } \\
\text { others }(\%)\end{array}$ & $p^{\mathrm{b}}$ \\
\hline Environment & .11 & .001 & 34.3 & 9.0 & 56.7 & .007 \\
\hline Animal protection & -.18 & .001 & 62.2 & 7.6 & 30.3 & .001 \\
\hline World hunger & -.21 & .001 & 62.1 & 15.4 & 22.5 & .001 \\
\hline
\end{tabular}

aSignificance levels refer to two-tailed $t$ tests of the null hypothesis that the mean rating is equal to zero ("exactly average"). bSignificance levels refer to goodness-of-fit tests of the null hypothesis that frequencies in the more than others and less than others categories are equal. 
As seen in Table 5, self-deprecation in activism ratings was again found for the issues of animal protection $(M=-0.18), t(184)=-6.36, p<.001$, and world hunger $(M=-0.21), t(181)=-6.43, p<.001$. On both of these issues, more than $60 \%$ of respondents said that they did less than did other people of their age and gender. Goodness-of-fit tests on these scores were highly significant for both animal protection, $\chi^{2}(2, N=185)=20.36, p<.001$, and world hunger, $\chi^{2}(2, N=182)=33.66, p<.001$. In contrast, respondents showed self-enhancement in ratings of environmental activism $(M=0.11), t(177)=3.90, p<.001$ In this case, the majority of respondents $(57 \%)$ reported doing more than others of their age and gender. A goodness-of-fit test on these scores led to a rejection of the null hypothesis, $\chi^{2}(2, N=178)=9.88, p<.008$, showing self-enhancement in ratings of environmental activism.

Debiasing conditions. To assess the effectiveness of the cognitive consistency debiasing technique, a $3 \times 3$ (Condition: Replication, Consistency/ Public, Consistency/Private $\times$ Issue: Environment, Animal Protection, World Hunger) analysis of variance was conducted on self-ratings of concern from the first part of the survey. The analysis revealed a main effect for issue, $F(2,807)=3.41, p<.05$, but no significant effect for condition, $F(2,807)=$ $0.43, n s$, or the Issue $\times$ Condition interaction, $F(4,807)=1.20, n s$. Thus, selfenhancement in concern was not significantly reduced when respondents were first asked to rate their level of activism.

To assess the effects of the salience debiasing technique, ratings of concern from the first part of the survey were compared with ratings of concern following the open-ended question. Because the former ratings did not differ significantly across the replication, consistency/public, and consistency/private conditions, ratings of concern in the first part of the survey were collapsed across all three conditions. Two-tailed $t$ tests revealed no significant differences due to the salience manipulation: for the environment, $t(540)=-1.31, n s$; for animal protection, $t(549)=1.93, n s ;$ and for world hunger, $t(538)=0.51$, $n s$. Thus, the salience debiasing technique, too, failed to reduce self-enhancement in concern

Additional findings. Responses to the question on the public's concern about the environment closely matched those that were obtained in the pilot study and the national survey by the Gallup Poll (1991): 67.9\% reported that the public is not worried enough about the environment (vs. $67.0 \%$ in the pilot and $70 \%$ nationally), $24.4 \%$ said that the public shows the right amount of concern (vs. $24.2 \%$ in the pilot and $22 \%$ nationally), and $7.7 \%$ reported that the public is too worried (vs. $8.8 \%$ in the pilot and $6 \%$ nationally). The equivalent percentages for the issue of world hunger were $61.9 \%, 30.3 \%$, and $7.8 \%$, and the figures for animal protection were $45.2 \%, 41.3 \%$, and $13.5 \%$. In all three issues, then, a plurality of respondents reported that others are not concerned enough.

The fact that respondents saw the public as insufficiently concernedeven while reporting, in two of three issues, that they themselves did less than others-suggests that respondents attended to different information when assessing their own concern and the concern of others. Supporting evidence on this point comes from two questions in which respondents were asked about the best way to measure concern. In answer to the question of whether feelings or actions were a better measure of citizen concern, $86.2 \%$ said that actions were a better measure. When asked which of the two was a better measure of their own concern, however, only $56.2 \%$ of respondents said that actions were more important. Indeed, the majority of respondents reported feeling more concern than their actions showed $(52.4 \%$ for the environment, $55.5 \%$ for animal protection, and $67.7 \%$ for world hunger). Furthermore, many respondents expressed a reluctance to act until others were more concerned about the issues in question. When respondents were asked whether they would do more if other people showed greater concern, $61.8 \%$ said they would do more to protect the environment, $44.1 \%$ said they would do more to protect animals, and $56.0 \%$ said they would do more to end world hunger.

\section{Discussion}

Once again, respondents showed self-enhancement in social concern across all issues examined, yet rated themselves as less active than others on each issue except the environment. These findings closely replicate those obtained in the pilot study. Moreover, respondents in this study were randomly selected from the general public, the interviewers were highly trained, and the data were collected via telephone, rather than in face-to-face encounters. Thus, this study does not suffer from several limitations of the pilot study.

Although social desirability biases are less likely in telephone interviews than in face-to-face interviews (Frey, 1989), it is, of course, still possible that respondents were simply giving socially desirable responses. This explanation is unlikely, however, for there is no obvious reason why social demand characteristics would simultaneously lead to self-enhancement in concern and self-deprecation in activism. Nevertheless, to help rule out this possibility, a sample of 49 college students was asked to provide self-ratings in concern and activism as if they were "a member of the general public whose main goal was to give the most socially desirable response to each question" (using the same items and rating scales as in the telephone survey). These ratings differed significantly from those obtained in the telephone survey, showing a uniform pattern of self-enhancement for activism as well as concern, and reflecting 
even higher ratings of concern than those found in the present study. It seems, then, that social desirability biases cannot easily account for the present results

Findings from the telephone survey indicate that self-enhancement in concern is a robust phenomenon spanning a variety of issues. Neither the consistency debiasing technique (in which respondents considered their activism before rating their concern) nor the salience debiasing technique (in which respondents considered the activism of others) succeeded in reducing selfenhancement biases. While the interpretation of null results is always problematic, one possibility is that self-ratings of concern are not based on selfperceived activism. Support for this explanation can be found in the tendency of many people to identify feelings as the best measure of their own concern but actions as the best measure of other people's concern.

The present findings also suggest that self-enhancement biases may contribute to a social dilemma in which people are unwilling to act unless others do more to show their concern. Depending on the issue involved, $45-68 \%$ of respondents said that the public was insufficiently concerned, and $44-62 \%$ said they would do more if others showed greater concern. Although saying that they would do more does not necessarily mean that they would do more (Fishbein \& Ajzen, 1975), these findings suggest that some respondents may have felt reluctant to act in the face of perceived indifference on the part of others.

\section{General Discussion}

These findings extend past research on self-enhancement in a number of ways. First, prior work had not examined self-enhancement in social concernan area in which the presence of biases may have profound societal consequences. Second, unlike many previous studies, self-enhancement was investigated in a random sample of the general public, rather than in a convenience sample of college students. Third, multiple ways of assessing selfenhancement were employed, allowing for comparisons among different measures and analyses. Fourth, an effort was made to understand the processes underlying self-enhancement in social concern, although this evidence is preliminary and serves mainly to suggest future directions for research.

With the exception of a few studies on unrealistic optimism (e.g., Weinstein, 1983; Weinstein \& Lachendro, 1982), the present research was also unique in that it explored techniques for debiasing self-enhancement. While the failure of these techniques certainly does not mean that self-enhancement is immutable, it does indicate that this bias is not simply a function of such factors as question order or the failure to consider actions that other people take. In fact, the rather dramatic finding that people will rate themselves as more concerned than others immediately after declaring that they do less than others is reminiscent of earlier studies on the tenacity of positive self-evaluations. In one such study, Preston and Harris (1965) found that automobile drivers who were hospitalized after serious accidents were just as likely as accident-free drivers to rate their driving ability near the "expert" end of a rating scale. In another study, van der Velde, van der Pligt, and Hooijkaas (1992) found that patients at a treatment clinic for sexually transmitted diseases rated their risk of syphilis as less than average compared with others of their gender and age. And in a study on self-perceptions concerning the chances of an unwanted pregnancy, Burger and Burns (1988) found that even after some of their subjects became pregnant, an illusory sense of future invulnerability persisted

The present results are also consistent with past research on the factors that moderate self-enhancement. For example, the pattern of self-enhancement in concern but not activism coincides with the finding that self-enhancement takes place only when the evaluative dimension is ambiguous (Allison et al., 1989; VanYperen, 1992). Previous studies have also shown that self-serving biases are less likely when people perceive the rated dimension as beyond their control (Alicke, 1985; Holland, 1993; Weinstein, 1982), which may, when coupled with perceived shortfalls of time and money, explain why self-enhancement was not found in ratings of activism. Thus, past studies on the ambiguity and perceived controllability of the dimension are consistent with the observed discrepancy between self-rated concern and activism.

One finding that was not central to this study, but which merits further attention, was the difference in ratings found among the issues. For instance, despite the prevalence of self-deprecation with respect to activism, respondents in the main study said that they were more active than others when it came to the environment (consistent with van der Pligt's [1984] finding that people underestimate the energy conservation behavior of others). As mentioned earlier, this difference may be due to high rates of participation in environmental activities. Commonplace activities such as recycling and conserving resources may serve as "token" actions that lead people to think that they are doing more than others. If so, it would be worth examining whether the effect of such tokenism is actually to depress involvement in other activities to protect the environment, much the same as donating change to a black panhandler can reduce subsequent compliance with larger requests to help promote racial harmony (Dutton \& Lennox, 1974).

Finally, future research might explore whether self-enhancement biases in concem are more likely in some individuals than in others. Although gender differences in self-enhancement are typically minimal, some investigations have reported significant differences based on age (Brandt, 1958; Holland, 1993) and personality characteristics such as self-esteem (Brown, 1986; Felson, 1981) and narcissism (John \& Robins, 1994). In order to understand the mechanisms 
underlying self-enhancement biases, future work should explore not only the domains in which such biases are found, but the subpopulations in which they are most likely to occur.

\section{References}

Alicke, M. D. (1985). Global self-evaluation as determined by the desirability and controllability of trait adjectives. Journal of Personality and Social Psychology, 49, 1621-1630.

Allison, S. T., Messick, D. M., \& Goethals, G. R. (1989). On being better but not smarter than others: The Muhammad Ali effect. Social Cognition, 7 , 275-296.

Baumhart, R. (1968). An honest profit: What businessmen say about ethics in business. New York, NY: Holt, Rinehart, \& Winston.

Blackburn, R. T., Pellino, G. R., Boberg, A., \& O'Connell, C. (1980). Are instructional improvement programs off-target? Current Issues in Higher Education, 2, 32-48.

Brandt, R. M. (1958). The accuracy of self estimate: A measure of self-concept reality. Genetic Psychology Monographs, 58, 55-99.

Brim, O. G., Neulinger, J., \& Glass, D. C. (1965). Experiences and attitudes of American adults concerning standardized tests (Technical Report No. 1 on the Social Consequences of Testing). New York, NY: Russell Sage Foundation.

Brown, J. D. (1986). Evaluations of self and others: Self-enhancement biases in social judgments. Social Cognition, 4, 353-376.

Burger, J. M., \& Burns, L. (1988). The illusion of unique invulnerability and the use of effective contraception. Personality and Social Psychology Bulletin, 14, 264-270.

Chaiken, S., \& Baldwin, M. W. (1981). Affective-cognitive consistency and the effect of salient behavioral information on the self-perception of attitudes. Journal of Personality and Social Psychology, 41, 1-12.

College Entrance Examination Board. (1977). National report on college bound seniors. Princeton, NJ: Educational Testing Service.

Dutton, D. G., \& Lennox, V. L. (1974). Effect of prior "token" compliance on subsequent interracial behavior. Journal of Personality and Social Psychology, 29, 65-71.

Felson, R. B. (1981). Ambiguity and bias in the self-concept. Social Psychology Quarterly, 44, 64-69.

Fishbein, M., \& Ajzen, I. (1975). Belief, attitude, intention, and behavior: An introduction to theory and research. Reading, MA: AddisonWesley.
Frey, J. H. (1989). Survey research by telephone (2nd ed.). Newbury Park, CA: Sage.

Furnham, A., \& Dowsett, T. (1993). Sex difference in social comparison and uniqueness bias. Personality and Individual Differences, 15, 175-183.

Gallup Poll. (1991, April). Americans report high levels of environmental concern, activity. Gallup Poll Monthly, 6-12.

Heiss, J., \& Owens, S. (1972). Self-evaluations of blacks and whites. American Journal of Sociology, 78, 360-370.

Hines, J. M., Hungerford, H. R., \& Tomera, A. N. (1986). Analysis and synthesis of research on responsible environmental behavior: A metaanalysis. Journal of Environmental Education, 18, 1-8.

Holland, C. A. (1993). Self-bias in older drivers' judgments of accident likelihood. Accident Analysis and Prevention, 25, 431-441.

John, O. P., \& Robins, R. W. (1994). Accuracy and bias in self-perception: Individual differences in self-enhancement and the role of narcissism. Journal of Personality and Social Psychology, 66, 206-219.

Kirscht, J. P., Haefner, D. P., Kegeles, S. S., \& Rosenstock, I. M. (1966). A national study of health beliefs. Journal of Health and Human Behavior, 7, 248-254.

Larwood, L. (1978). Swine flu: A field study of self-serving biases. Journal of Applied Social Psychology, 8, 283-289.

Lehman, D. R., \& Taylor, S. E. (1988). Date with an earthquake: Coping with a probable, unpredictable disaster. Personality and Social Psychology Bulletin, 13, 546-555.

Perloff, L. S. (1983). Perceptions of vulnerability to victimization. Journal of Social Issues, 39(2), 41-61.

Plous, S. (1993). Psychological mechanisms in the human use of animals. Journal of Social Issues, 49, 11-52.

Preston, C. E., \& Harris, S. (1965). Psychology of drivers in traffic accidents. Journal of Applied Psychology, 49, 284-288.

Robertson, L. S. (1977). Perceived invulnerability and willingness to pay for crash protection. Journal of Community Health, 3, 136-141.

Segerstrom, S. C., McCarthy, W. J., Caskey, N. H., Gross, T. M., \& Jarvik, M. E. (1993). Optimistic bias among cigarette smokers. Journal of Applied Social Psychology, 23, 1606-1618.

Svenson, O. (1981). Are we all less risky and more skillful than our fellow drivers? Acta Psychologica, 47, 143-148.

Taylor, S. E., \& Brown, J. D. (1988). Illusion and well-being: A social psychological perspective on mental health. Psychological Bulletin, 103, 193-210.

Tyler, T. R., \& McGraw, K. M. (1983). The threat of nuclear war: Risk 
interpretation and behavioral response. Journal of Social Issues, 39, 25-40.

van der Pligt, J. (1984). Attributions, false consensus, and valence: Two field studies. Journal of Personality and Social Psychology, 46, 57-68.

van der Velde, F. W., van der Pligt, J., \& Hooijkaas, C. (1992). Risk perception and behavior: Pessimism, realism, and optimism about AIDS-related health behavior. Psychology and Health, 6, 23-28.

VanYperen, N. (1992). Self-enhancement among major league soccer players: The role of importance and ambiguity on social comparison behavior. Journal of Applied Social Psychology, 22, 1186-1198.

Weinstein, N. D. (1982). Unrealistic optimism about susceptibility to health problems. Journal of Behavioral Medicine, 5, 441-460.

Weinstein, N. D. (1983). Reducing unrealistic optimism about illness susceptibility. Health Psychology, 2, 11-20.

Weinstein, N. D. (1987). Unrealistic optimism about susceptibility to health problems: Conclusions from a community-wide sample. Journal of Behavioral Medicine, 10, 481-500.

Weinstein, N. D., \& Lachendro, E. (1982). Egocentrism as a source of unrealistic optimism. Personality and Social Psychology Bulletin, 8, 195-200.

Wylie, R. C. (1979). The self-concept: Vol. 2. Theory and research on selected topics (rev. ed.). Lincoln, NE: University of Nebraska Press. 